\title{
Antigen Detection of Bovine Rotavirus Infection in Diarrheic Crossbred Dairy Calves Reared by Holeta Research Center, Oromiya Region Ethiopia
}

\author{
Beksisa U*, Melese E,Helen A,Tamirat Si, Markos T, Temesgen K and Neima A \\ Ethiopian Institute of Agricultural Research, Holeta Research center, Ethiopia \\ *Corresponding author: Beksisa U, Ethiopian Institute of Agricultural Research, Holeta Research center, Ethiopia
}

\section{ARTICLE INFO}

Received: 蔧 July 18, 2020

Published: 慧 September 10, 2020

Citation: Beksisa U, Melese E,Helen A,Tamirat Si, Markos T, Temesgen K, Neima A. Antigen Detection of Bovine Rotavirus Infection in Diarrheic Crossbred Dairy Calves Reared by Holeta Research Center, Oromiya Region Ethiopia. Biomed J Sci \& Tech Res 30(2)-2020. BJSTR. MS.ID.004925.

Keywords: Calves; Prevalence; Risk Factors, Rotavirus

\section{ABSTRACT}

Rotaviruses are considered as a major cause of diarrhea in calves and it causes calf morbidity, mortality and substantial economic losses in the dairy industry. A crosssectional study design was conducted from November 2018 to April 2019 in order to investigate the incidence of recent bovine rotavirus infection and its associated risk factors in neonatal crossbred calves in Holeta research center, dairy farm central Oromiya, Ethiopia. All clinically diseased crossbred calves were purposively sampled, and apparently healthy ones were randomly selected to detect recent diarrhea cases in the farm. A total of 60 accessible crossbred calves from diarrheic $(n=42)$ and non-diarrheic $(n-=18)$ categories under the age of ninety days were diagnosed for rotavirus infection. The overall rotavirus infection in the crossbred calves of the farm was $5 \%$. The infection of rotavirus in the first week of calf ages (1-10 days) was $12.5 \%$ and that of (10-30 days) was $4.2 \%$. The infection rate of rotavirus in female and male crossbred calves were $7.14 \%$ and $4.35 \%$ respectively. The study showed that rotavirus infection is responsible for neonatal calf diarrhea, morbidity and mortality in the farm. Therefore, a comprehensive study on neonatal calf diarrhea attributable to other potential enteropathogens should be executed to apply a coordinated control program efficiently to reduce resulted calf mortality in the study farm.Hence, it is imperative to determine the disease burden and genotyping of rotavirus to execute effective preventive measures among the population at higher risk.

\section{Introduction}

Neonatal calf diarrhea is one of the leading causes of calf mortality, morbidity and economic losses in the dairy industry. It is caused by multifactorial infectious agents [1]. Bovine rotavirus, Coronavirus, Cryptosporidium and Escherichia coli are the potential enteropathogens collectively responsible for 75\% -95\% of infection in newborn calves worldwide [2]. Among these causal agents, rotavirus agents' leads to severe enteritis in young animals[3] and causes $27-36 \%$ diarrhea in neonate calves [4,5]. Rotavirus is a member of the family reoviridae which is characterized by nonenveloped, segmented and double stranded RNA genome. There are distinct groups of rotaviruses named as A to $\mathrm{H}$, based on their antigenic property of the VP6 protein; among these, rotavirus A
(RVA) shows more diversity [6]. Epidemiological studies revealed that calves are more vulnerable to rotavirus infection at 1-3 weeks of age and age is one of the most important influencing factors of rotavirus $[7,8]$. Colostrum contains specific antirotaviral antibodies that prevent infection and diarrhea at an early age, while it declines rapidly, and about three days post-partum the concentration becomes non-protective [9].

Results of several investigations pointed out that mixed infections are more common in calves at an early age than infections with single pathogens and rotavirus infection usually occurs in combination with E. coli or other virus, might lead to high mortality[7,8]. However, the morbidity rate varies from herd to 
herd; the survival of rotavirus in air and on surfaces is influenced by the air humidity[7]. Limited and fragmented studies so far conducted in Ethiopia indicated that the incidence of neonatal calf diarrhea varies from $20.05 \%$ to $52.51 \%$ [10] and Seid [11] also reported $33.88 \%$ diarrhea and the prevalence of $2.45 \%$ rotavirus infection in calves less than four weeks of age. It has been indicated that about $75 \%$ of early calf mortality in the dairy herd is caused by acute diarrhea in the pre-weaning period [12]. Diagnosis of neonatal diarrhea is difficult due to the presence of asymptomatic infections, associated agents and other factors [13]. Laboratory diagnostic methods such ELISA is used for detecting rotavirus antigens in the feces of diarrheic calves [14].

Several factors were responsible for influencing the severity of rotavirus infection in calves. Factors like intake of colostrum, age and health status of the calves, immune status of the dam, degree of exposure and virulence of the virus, and the presence of secondary pathogens were revealed as key parameters[8]. Few studies concerning bacterial and parasitic neonatal calf diarrhea has been executed, but research studies concerning rotavirus infection in calves is substantially low. There was also limited information on the incidence of rotavirus infection in crossbred calves of HARC. Understanding the occurrence of rotavirus infection in calves and its associated risk factors is vital. Hence, detecting the circulating rotavirus is needed for proper control and preventive measures in the farm. Therefore, the current study was designed to detect rotavirus from recent diarrhea cases in neonatal crossbred calves.

\section{Materials and Methods}

\section{Study Area}

Holeta Town is located in the central part of the country, 34 $\mathrm{km}$ west of Addis Ababa in Oromia Regional state, west Shewa Administrative Region at an elevation of 2400 m.a.s.l in the central high land of Ethiopia. The area is bounded between latitude 80 $53^{\prime} 75^{\prime \prime}$ to 90 o $14^{\prime}$ North and longitude 38 o $21^{\prime} 40^{\prime \prime}$ to 38 o $36^{\prime} 14^{\prime \prime}$ East. The area also experience bimodal rainfall pattern with a long rainy season extends from June to September while the short rainy season extends from March to April. The annual mean maximum and the minimum temperatures are 25.9 and $7.20 \mathrm{C}$, respectively [15].

\section{Study Calves}

The study was conducted in sick and calves having clinical sign of diarrhea such as profuse and watery diarrhea, systemic dehydration and depressed. Apparently heathy calves were also included in the study. Calf factors such as age groups, blood level and sex were included in the study. Crossbred dairy calves that aged below 90 days in the farm were a part of this study. Diarrhea was considered if feces are semi-liquid to liquid, with or without other abnormal characteristics like presence of blood or mucous. Dairy calves with feces that had not manifested these characteristics was considered non-diarrheic or apparently healthy calves [16].

\section{Study Design and Sample Size Determination}

A cross-sectional study was conducted in the HARC dairy farm from November 2018 to April 2019 in order to determine the incidence of rotavirus infection in diarrheic calves. About 42 calves with history of diarrhea cases and 18 apparently healthy calves were investigated during the entire period of this study.

\section{Sampling Technique}

Purposive sampling technique was employed to sample clinically diseased calves where as non-diseased calves were randomly sampled to detect rotavirus infection in the farm. The sampling units were crossbred dairy calves (50\%, and 75\%) that aged between births to 90 days of age.

\section{Collection and Processing of Fecal Samples}

Fecal samples were collected during episodes or outbreaks of diarrhea in calves and approximately 30 grams of fecal material was collected directly from the rectum of diarrheic calves using disposable latex glove. Fecal samples were also collected from apparently healthy calves. The samples were processed, and laboratory analysis was done.

\section{Rotavirus Antigen Detection by ELISA}

Fecal samples collected from diarrheic cases were tested using a commercial Ag ELISA kit for rotavirus (Antigenic ELISA kit for detection of rotavirus, Bio K 314/1, Diagnostics; Belgium) was used to detect bovine rotavirus antigen in the fecal samples. The ELISA procedure was performed according to manufacturer instruction. The ELISA was performed to detect rotavirus antigen in the fecal samples of diarrheic calves. The 96 well plates provided in the kit contained captured antibodies. Rows C, E, D, F, H and G were coated with rotavirus specific capture antibodies and rows $\mathrm{A}$ and B coated with non-specific antibodies, which is acted as positive and negative control. These control rows allow the differentiation between specific immunological reaction and non-specific bindings so as to eliminate false positives. Fecal suspensions were diluted in the dilution buffer provided in the kit and a volume of $100 \mu \mathrm{l}$ of diluted sample was added to corresponding wells of specific and non-specific antibody coated rows, respectively. Similarly, both the positive and negative controls were added to their respective well per plate.

The plate was incubated at $25^{\circ} \mathrm{C}$ for 0.5 hour and washed 3 times with washing solution provided in the kit. Ready to use conjugate of rotavirus specific monoclonal antibody labelled peroxidase was used as such and poured in $100 \mu \mathrm{l}$ quantities per well. The plates were covered with a lid and incubated at $25^{\circ} \mathrm{C}$ for 0.5 hour in a dark room and washed three times with the provided washing buffer. Then $100 \mu \mathrm{l}$ of the chromogen solution added to each well on the plate. The plates were then incubated for 10 minutes at $25^{\circ} \mathrm{C}$. Finally, the reaction was stopped by adding stop solution provided in the kit. The optical density was measured at $450 \mathrm{~nm}$ after stopping the 
reaction with $50 \mu$ l per well of stop solution. The optical density was measured at $450 \mathrm{~nm}$ using an ELISA plate reader at $450 \mathrm{~nm}$ immediately after stopping the reaction with the stop solution. The net optical density of each sample was calculated by subtracting the reading for each sample well from corresponding negative control. Net optical density (O.D.) $=$ (O.D. of specific binding -O.D. of non-specific binding. Even positive and negative reaction results in ELISA was decided based on color changes after adding stop solution as well as calculating the optical density value.

\section{Data Management and Analysis}

Putative factors associated with the occurrence of rotavirus infection and serological results were recorded in a Microsoft Excel Spread Sheet. The proportions of fecal samples positive to rotavirus

Table 1: Rotavirus infection in diarrheic crossbred dairy calves. variables such as age group and sex of the calves was studied by using Chi Square. Quantitative data was coded and entered in a computer spread sheets and the Stata 13 software was used for the data analysis.

\section{Results}

\section{Determining Rotavirus Infection in Diarrheic Crossbred Calves}

The results indicated that out of 60 calves examined for diarrhea cases, about $4.76 \%$ and $5.65 \%$ were positive for rotavirus infection in clinically diarrheic and apparently healthy calves. Hence, the overall prevalence of rotavirus infection in the farm was $5 \%$ (Table 1).

\begin{tabular}{|c|c|c|c|}
\hline Crossbred Calf Category & No of Calves (N) & No. Positive to Rotavirus Infection & Percentage(\%) \\
\hline Clinically Diarrheic Calves & 42 & 2 & 4.76 \\
\hline Apparently Healthy Calves & 18 & 1 & 5.65 \\
\hline Total & 60 & 3 & 5 \\
\hline
\end{tabular}

\section{Risk Factors Associated with Rotavirus Infection in Crossbred Calves}

Age Related Difference in the Occurrence of Rotavirus Infection in Calves: The overall prevalence of rotavirus infection in the first week of calf ages (1-10 days) and (10-30 days) was $12.5 \%$ and $4.2 \%$ respectively (Table 2 ).

Sex Related Difference in the Occurrence of Rotavirus
Infection in Calves: The overall prevalence of rotavirus infection in female and male crossbred calves were $7.14 \%$ and $4.35 \%$ respectively (Table 2).

Blood Level Difference in the Occurrence of Rotavirus Infection in Calves: The overall prevalence of rotavirus infection in $75 \%$ and $50 \%$ blood level crossbred calves was $11.1 \%$ and $2.38 \%$ respectively (Table 2).

Table 2: Antigen detection of rotavirus infection in crossbred calves by ELISA.

\begin{tabular}{|c|c|c|c|c|c|c|}
\hline \multicolumn{2}{|c|}{ Calf Health Parameters } & \multirow{2}{*}{$\begin{array}{c}\text { No of Diarrhea } \\
\text { Samples } \\
16\end{array}$} & \multirow{2}{*}{$\begin{array}{l}\text { No. Samples Positive } \\
\text { for Rota Virus } \\
2\end{array}$} & \multirow{2}{*}{$\begin{array}{c}\begin{array}{c}\text { Rota Virus } \\
\text { Infection (\%) }\end{array} \\
12.5\end{array}$} & \multirow{4}{*}{$\begin{array}{c}\text { Fisher's Exact Test } \\
\\
6.031\end{array}$} & \multirow{4}{*}{$\begin{array}{l}\text { P value } \\
0.005\end{array}$} \\
\hline \multirow{4}{*}{ Age Groups (in days) } & 1-10 days & & & & & \\
\hline & 10-30 days & 24 & 1 & 4.2 & & \\
\hline & 30-60 days & 12 & 0 & 0 & & \\
\hline & 60-90 days & 8 & 0 & 0 & & \\
\hline \multirow{2}{*}{ Sex } & Male & 14 & 1 & 7.14 & \multirow{2}{*}{1.89} & \multirow{2}{*}{0.531} \\
\hline & Female & 46 & 2 & 4.35 & & \\
\hline \multirow{2}{*}{ Blood Level } & $50 \%$ & 42 & 1 & 2.38 & \multirow{3}{*}{10.21} & \multirow{3}{*}{0.013} \\
\hline & $75 \%$ & 18 & 2 & 11.1 & & \\
\hline Overall & 60 & 3 & 5 & & & \\
\hline
\end{tabular}

The figure below indicated that the morbidity rate in female and male calves was $23 \%$ and $7 \%$ respectively and about $5 \%$ of females had died from rotavirus infection. The case fatality among calves mounted to $17 \%$ in the farm (Figure 1). 


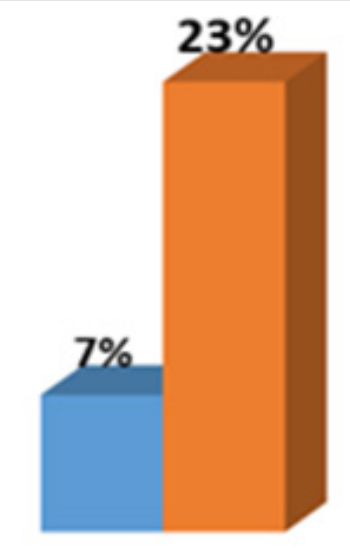

Morbidity rate

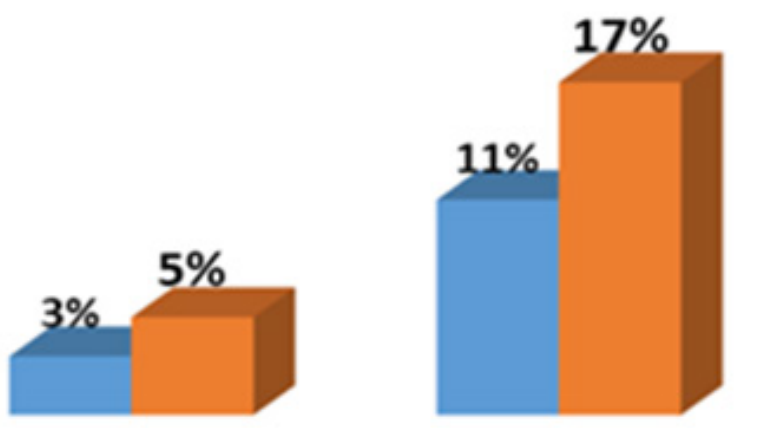

Male

Female

Figure 1: Sex wise calf morbidity and mortality rate in diarrheic crossbred calves.

\section{Discussion}

Neonatal calf diarrhea is a prime disease affecting newborn calves leading to morbidity and mortality in newborn calves, causing economic losses. Rotavirus infection is considered as the basic cause of diarrhea and enteritis in calves [17]. In the current study, the overall prevalence of rotavirus infection in clinically diarrheic and apparently healthy crossbred calves of less than 6 weeks of age was $5 \%$. The prevalence of infection was $4.76 \%$ in clinically diarrheic calves and 5.65\% in calves without the history of calf scour was notified. This result could also match with the previous findings of Seid [11] who reported the prevalence of 7.23\% rotavirus infection in calves in the central areas of Ethiopia. Other author such as [18] reported higher prevalence of rotavirus virus infection (16.7\%) Ethiopia. Similarly, Samad, et al. [19]reported $12 \%$ and $3 \%$ prevalence in diarrheic and non-diarrheic calves of Bangladesh, respectively. Remarkably, the prevalence of this viral infection was found much higher in other countries (11 to $45 \%$ ) in India [20], 15\% in Vietnam[9], 17\% in Brazil [21]. The differences in the prevalence of this infection might have been influenced by different factors such as management and host related factors, analytical strategy and the sensitivity of the diagnostic tests used.

The overall prevalence of rotavirus infection in calves in the first week of calf ages (1-10 days) and (10-30 days) was $12.5 \%$ and $4.2 \%$ respectively. The findings of the present study was in agreement with the earlier workers reported by Abraham, et al. $[18,22,23]$, higher occurrence of rotavirus infection in diarrheic calves were mainly restricted to the first 2 weeks of life. Maximum prevalence of rotavirus diarrhea was observed in 5-21 days old calves [24]. This could be highlighted by an increased natural resistance against infection in this age groups [16]. The occurrence of rotavirus in the fecal samples of diarrheic calves was found to decrease with increase in the age of the calves. The 2 weeks old calves were the most susceptible to rotavirus infections, which may be due to decreasing of passive immunity and the absence of the natural resistance against infection. This study also provides higher susceptibility in $<3$ weeks age calves was also observed by [25] who stated the highest prevalence in 22-30 days group (44.8\%) in contrast to other groups: 1-7 days (15.6\%), 8-14 days (12.3\%) and 15-21 days (13.2\%). However, the relation of age of calves with the prevalence of rotavirus infection is not consistent as some of the previous studies demonstrated higher frequency (33.77\%) in 8-14 days old age group compared to other age groups: $19.23 \%, 0 \%$ and $11.11 \%$ in $1-7,15-21,22-30$ days of age, respectively[16].

This could be related with progression of age and resistance against rotavirus infection in the second week of life. The study also revealed that bovine rotavirus infection seems to occur more frequently in male than female calves. Rotavirus infection may not occur in calves that have high levels of antibodies in their gut[26]. Avirulent strains of rotavirus, occurring in bovines may only cause sub clinical infection, despite colonization and replication in the enterocytes. On this basis, avirulent rotaviruses may be capable to provide protection against disease caused by the virulent virus [27].The clinical signs, diagnosis and epidemiology of the disease is similar to that observed in most of the animal species and the severity varies from subclinical infection to a severe enteritis and diarrhea. The current finding also revealed that there was higher rate of infection in $75 \%$ blood level $(11.1 \%)$ of calves than $50 \%$ blood level $(2.38 \%)$. This might be due to the fact that the clinical outcome is more evident in pure breeds and calves are known to excrete the virus through faeces by the secondary infection which continues for 7-8 days and susceptible calves of 2-3 weeks age may get infected [26]. 


\section{Conclusion}

The present study indicated that the circulation of rotavirus in the farm is responsible for neonatal diarrhea and morbidity of crossbred calves. This was performed through clinical and serological screenings. The overall prevalence of rotavirus infection in clinically diarrheic and non-diarrheic crossbred calves of less than 6 weeks of age was 5\%. About $4.76 \%$ and $5.65 \%$ of prevalence was notified in clinically diarrheic calves and calves without the history of scour respectively. Age, sex and blood level of calves were identified as the potential risk factors contributing to the transmission dynamics of the virus in the study farm. However, genotyping of BRV field strain is essential for development of more specific preventive strategies and future immunization approaches.

\section{References}

1. Al Robaiee IA, MI Al Farwachi (2013) Prevalence of rotavirus infection in diarrheic neonatal calves in Mosul city, Iraq. Vet World 6(8): 538-540.

2. Suresh T, Rai RB, Dhama K, Rai S, Sawant PM, et al. (2011) Pathology of rotavirus infection in calves and detection of viral antigen by ELISA and FAT. Indian J Vet Pathol 35(1): 1-3.

3. Martella V, Bányai K, Matthijnssens K, Buonavoglia C, Ciarlet M (2010) Zoonotic aspects of rotaviruses. Vet Microbiol 140(2-3): 246-255.

4. Chauhan R, N Singh (1996) Epidemiology of rotavirus infection in calves in India. Int J Anim Sci 11: 221-223.

5. Cho Y, Yoon K (2014) An overview of calf diarrhea-infectious etiology, diagnosis, and intervention. J Vet Sci 15(1): 1-17.

6. Matthijnssens J, Desselberger U (2012) Genome diversity and evolution of rotaviruses. Genome Plasticity and Infectious Diseases. Am Soc Microbiol 13: 214-241.

7. Radostitis O, Gay C, D Blood and K Hinchcliff (2000) Veterinary medicine ( $9^{\text {th }}$ Edn.). WB Sauder's. London, UK.

8. Dhama K, Chauhan RS, Mahendran M, Malik S (2009) Rotavirus diarrhea in bovines and other domestic animals. Vet Res Commun 33(1): 1-23.

9. Kyle H (2007) Infection of rotavirus in dairy calves in South Vietnam. Department of Clinical Sciences. Swedish University of Agricultural Sciences, Uppsala, Sweden, p. 1-19.

10. Malik S, Verma A, Kumar A, Gupta M, Sharma S (2012) Incidence of calf diarrhea in cattle and buffalo calves in Uttar Pradesh, India. Asian J Anim Vet Adv 7: 1049-1054.

11. Seid U (2019) Isolation and characterization of rotavirus associated with calf diarrhea in the central part of Oromia Ethiopia, Mvsc Thesis.

12. Bartels C, Holzhauer M, Jorritsma R, Swart W, Lam T (2010) Prevalence, prediction and risk factors of enteropathogens in normal and non- normal feces of young Dutch dairy calves. Prev Vet Med 93(2-3): 162169.

13. Athanassious R, Marsolais G, Assaf R, Dea S, Dulude S, et al. (1994) Detection of bovine coronavirus and type A rotavirus in neonatal calf diarrhea and winter dysentery of cattle in Quebec: evaluation of three diagnostic methods. Can Vet J 35(3): 163-169.

14. Mayameei A, Mohammadi G, Yavari S, Afshari E, Omidi A (2010) Evaluation of relationship between Rotavirus and Coronavirus infections with calf diarrhea by capture ELISA. Comp Clin Path 19(6): 553-557.

15. (2009) HTRAD0, Holeta Town Rural Agricultural Development Office. Annual summary of work report. Unpublished report 24.

16. Ammar S, Mokhtaria K, Tahar B, Amar A, Redha B, et al. (2014) Prevalence of rotavirus and coronavirus associated with neonatal diarrhea in calves in western Algeria. Asian Pac J Trop Biomed 4(Suppl 1): S318-S322.

17. Rathi R, Kadian S, Khurana B, Grover YP, Gulati BR (2007) Evaluation of immune response to bovine rotavirus following oral and intraperitoneal inoculation in Mice. Indian Journal of Experimental Biology 45(2): 212216.

18. Abraham G, Roeder P, Zewdu R (1992) Agents associated with neonatal diarrhea in Ethiopian dairy calves. Trop Anim Health Prod 24(2): 74-80.

19. Samad MW, Ahmed MA (1990) Epidemiological investigation of rotavirus infection in buffalo calves in Bangladesh. In, Proceeding of Domestic Buffalo Production in Asia, Mymensingh, Bangladesh, p. 195-200.

20. Rai R, A Hansha, S Rai, B Singh, H Kumar, et al. (2011) Prevalence of rota and coronavirus infections in calves of Barabanki and Raebareli districts of Uttar Pradesh. Indian J Vet Pathol 35(1): 73-74.

21. Alfieri A, ME Parazzi, E Takiuchi, KC Médici (2006) Frequency of group A rotavirus in diarrheic calves in Brazilian cattle herds, 1998-2002. Trop Anim Health Prod 38(7): 521-526.

22. Jindal S, N Maiti, M Oberoi (2000) Genomic diversity and prevalence of Rotavirus in cow and buffalo calves in northern India. Rev Sci Tech 19(3): 871-876.

23. Singh D, Kumar M, Choudhary P, Singh H (2009) Neonatal calf mortalityan overview. Intas Poli vet 10(2): 165-169.

24. Radostits O, Gay C, Hinchcliff K, Constable P (2007) A textbook of the diseases of cattle, horses, sheep, pigs and goats. Vet Med 10: 2045-2050.

25. Garcia A, Ruiz Santa Quiteria JA, Orden J, D Cid, R Sanz, et al. (2000) Rotavirus and concurrent infections with other enteropathogens in neonatal diarrheic dairy calves in Spain. Comp Immunol Microbiol Infect Dis 23(3): 175-183.

26. Steele A, Geyer A, Gerdes G (2004) Rotavirus infections. Infectious Diseases of Livestock, Oxford University Press, Southern Africa, pp. 1256-1264.

27. Bridger J, Pocock D (1986) Variation in virulence of bovine rotaviruses. J Hyg 96(2): 257-264.
ISSN: 2574-1241

DOI: $10.26717 /$ BJSTR.2020.30.004925

Beksisa U. Biomed J Sci \& Tech Res

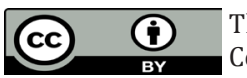

This work is licensed under Creative Commons Attribution 4.0 License

Submission Link: https://biomedres.us/submit-manuscript.php

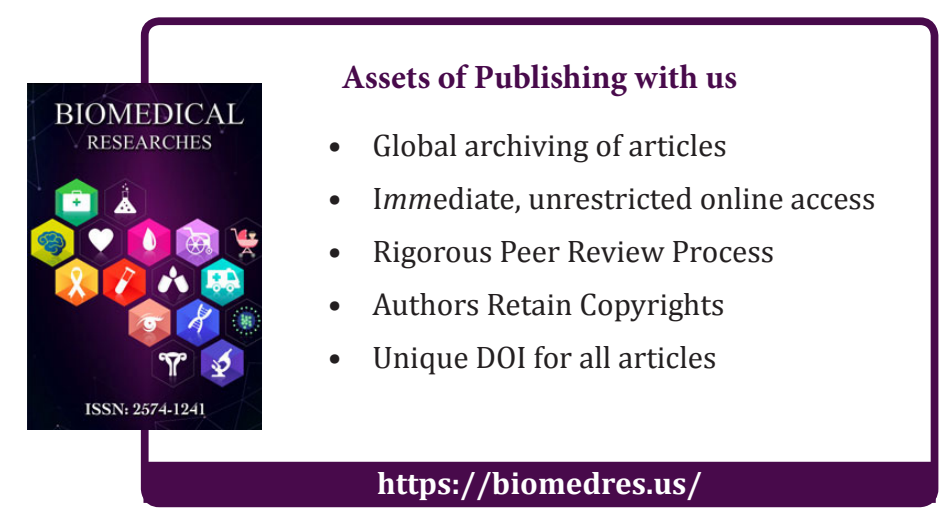

